\title{
Association between non-high-density lipoprotein cholesterol and haemorrhagic transformation in patients with acute ischaemic stroke
}

\section{Yanan Wang ( $\sim 723684533 @ q q . c o m$ )}

West China hospital, Sichuan University https://orcid.org/0000-0002-3089-9462

\section{Quhong Song}

Sichuan University West China Hospital

\section{Yajun Cheng}

Sichuan University West China Hospital

\section{Chenchen Wei}

Sichuan University West China Hospital

\section{Chen Ye}

Sichuan University West China Hospital

Junfeng Liu

Sichuan University West China Hospital

\section{Bo Wu}

Sichuan University West China Hospital

\section{Ming Liu}

Sichuan University West China Hospital

\section{Research article}

Keywords: Non-high-density lipoprotein cholesterol, Haemorrhagic transformation, Acute ischaemic stroke

Posted Date: October 11th, 2019

DOl: https://doi.org/10.21203/rs.2.15918/v1

License: (c) (1) This work is licensed under a Creative Commons Attribution 4.0 International License. Read Full License

Version of Record: A version of this preprint was published at BMC Neurology on February 7th, 2020. See the published version at https://doi.org/10.1186/s12883-020-1615-9. 


\section{Abstract}

Background: It is unclear whether non-high-density lipoprotein cholesterol (Non-HDL-C) is associated with haemorrhagic transformation (HT) after acute ischaemic stroke (AIS). We aimed to explore the association between Non-HDL-C and HT, as well as compare predictive values of Non-HDL-C and lowdensity lipoprotein cholesterol (LDL-C) for HT.

Methods: We consecutively enrolled AIS patients within 7 days of stroke onset. Participants were divided into four categories according to quartiles of Non-HDL-C. HT was assessed by follow-up brain imaging. We assessed the association between Non-HDL-C, LDL-C and HT.

Results: A total of 2043 patients were included, among whom 232 were identified as HT. Compared with the highest quartiles, the first, second and third quartiles of Non-HDL-C were associated with increased risk of HT (adjusted Odds ratios [ORs] 1.74 [95\% Confidence Interval [Cl] 1.09-2.78], 2.01[95\% Cl 1.263.20], and 1.76 [95\% $\mathrm{Cl} 1.10-2.83$ ], respectively, $P$ for trend=0.024). Similar results were found for LDL-C. There was significant interaction between Non-HDL-C and age ( $P$ for interaction=0.021). The addition of Non-HDL-C and LDL-C to conventional factors significantly improved predictive values (Non-HDL-C, net reclassification index [NRI] $0.24,95 \% \mathrm{Cl} 0.17-0.31, \mathrm{P}<0.001$; LDL-C, NRI $0.15,95 \% \mathrm{Cl} 0.08-0.22, \mathrm{P}=0.03$ ).

Conclusions: Low Non-HDL-C was associated with increased risks of HT. In addition, Non-HDL-C has similar effects as LDL-C for predicting HT.

\section{Background}

Haemorrhagic transformation (HT) is a common complication after acute ischaemic stroke (AIS), occurring in about $10 \%-40 \%$ of patients[1]. The presence of HT may contribute to poor outcome in stroke patients[2]. A number of factors associated with HT have been reported, including age, stroke severity, atrial fibrillation and thrombolysis.

Although dyslipidemia is known as an important risk factor of stroke[3], the association between the serum lipid levels and HT has not been well established. Prior studies have stated that low level of lowdensity lipoprotein cholesterol (LDL-C) could increase HT in patients with AIS[4-7], whereas the relationship between non-high-density lipoprotein cholesterol (Non-HDL-C) and HT is still not clear. As a composite marker, Non-HDL-C includes the triglyceride-rich lipoproteins such as chylomicrons, LDL, verylow-density lipoproteins, and their remnant[8]. Recent studies demonstrated that Non-HDL-C was more strongly associated with cardiovascular diseases than LDL-C[9-11]. However, whether Non-HDL-C is superior to LDL-C for predicting HT has not been studied. Therefore, we aimed to explore the association between Non-HDL-C and HT, as well as compare the predictive values of Non-HDL-C and LDL-C for HT in patients with AIS.

\section{Methods}




\section{Study Population}

We consecutively enrolled ischaemic stroke patients within 7 days of stroke onset between January 2016 and September 2018 based on the Chengdu Stroke Registry Database, which has been described in details previously $[12,13]$. All patients were clinically diagnosed as ischaemic stroke based on the World health Organization criteria[14], and finally confirmed by computed tomography (CT) or magnetic resonance imaging (MRI) scan. Patients were not eligible if they: (1) were diagnosed with HT based on the initial head CT on admission, or (2) did not undergo later CT or MRI scan; or (3) lacked lipid profile test within 24 hours after admission.

\section{Data collection}

Baseline information including patients' demographics, stroke severity on admission, medical history, current smoking, alcohol consumption, systolic blood pressure (SBP), diastolic blood pressure (DBP), blood glucose, lipid parameters, the Trial of ORG 10172 in Acute Stroke Treatment (TOAST) classification, thrombolysis and thrombectomy were collected. Medical history contained hypertension, diabetes mellitus, hyperlipidemia and atrial fibrillation. Stroke severity on admission was evaluated using the National Institutes of Health Stroke Scale (NIHSS)[15].

\section{Lipid parameters}

Blood samples were collected within 24 hours after hospital admission, and serum lipid parameters, including total cholesterol (TC), triglycerides (TG), HDL-C and LDL-C, were tested in the Department of Laboratory Medicine, West China Hospital. Non-HDL-C levels were determined by subtracting serum HDLC levels from total cholesterol[16].

\section{Assessment of HT}

HT was defined as hemorrhage within the infarcted area or parenchyma hemorrhage outside the infarct zone that was present on a second CT or MRI (usually within $7 \pm 2$ days after admission), but not on head CT or MRI on admission, based on the European Cooperative Acute Stroke Study II criteria.[17]. HT was identified separately by two researchers (YW and QS), and a third researcher (CW) was consulted when a disagreement occurred.

\section{Statistical analysis}

Participants were divided into four categories according to quartiles of Non-HDL-C. Continuous variables are described as means with the standard deviations or median with interquartile ranges, and categorical variables are presented as proportions frequencies with percentages. Differences in continuous data were 
assessed using Student's $t$ test, ANOVA test, the Mann-Whitney $U$ test or the Kruskal-Wallis test and differences in categorical data were assessed using the chi-squared test. Univariate analysis was carried out to identify possible risk factors for $\mathrm{HT}$. We further performed multivariate logistic regression analysis to assess the association between Non-HDL-C or LDL-C and HT. The odds ratio (OR) and $95 \%$ confidence interval $(\mathrm{Cl})$ was calculated. We created 2 models. Model 1 adjusted for age and sex. Model 2 further adjusted for other potential confounding variables based on model 1. Multivariable spline regression model was used to test nonlinear relationship between LDL-C, Non-HDL-C and HT. In addition, C statistics and net reclassification index[18] were calculated to evaluate the predictive value of adding Non-HDL-C or LDL-C to conventional risk factors model. In addition, we performed stratified analyses to explore potential indicators that may modify the relationship between Non-HDL-C and HT. The significance of interaction was tested by the likelihood ratio test. All statistical analyses were performed using SPSS 22.0 (IBM, Chicago, IL, USA), R (http://www.R-project.org, The R Foundation) and EmpowerStats (http://www.empowerstats.com, X\&Y Solutions, Inc., Boston, MA, USA). Two-sided values of $P<0.05$ were considered statistically significant.

\section{Results}

\section{Baseline characteristics}

In all, 2206 consecutive patients with ischaemic stroke within 7 days were admitted to our hospital during the study period, 2043 patients were included in this study (Figure 1). Of these 2043 patients, the mean age was $65 \pm 14$ years, and $63.1 \%$ were males.

Demographic and clinical characteristics of participants based on Non-HDL-C quartiles are summarized in Table 1. Non-HDL-C levels ranged from 0.59 to $10.03 \mathrm{mmol} / \mathrm{L}$ (mean value, $3.14 \mathrm{mmol} / \mathrm{L}$ ). Patients were divided into four categories based on Non-HDL-C quartiles: Q1, $<2.35 \mathrm{mmol} / \mathrm{L} ; \mathrm{Q} 2,2.35-3.06$ $\mathrm{mmol} / \mathrm{L} ; \mathrm{Q} 3,3.07-3.83 \mathrm{mmol} / \mathrm{l}$ and Q4 3, >3.83 $\mathrm{mmol} / \mathrm{L}$. As shown in table 1, patients in the lowest quartile were more like to be older, have a higher proportion of atrial fibrillation, have higher NIHSS scores and HDL-C compared with those in the highest quartile of Non-HDL-C. In addition, patients in the highest quartile were more likely to be have a higher proportion of hypertension, diabetes mellitus, have higher SBP, DBP, glucose, TG, TC and LDL-C compared with those in the lowest quartile of Non-HDL-C.

Of the 2043 patients, 232 (11.4\%) were identified as HT. Incidence of HT was $14.0 \%$ in quartile1, $11.5 \%$ in quartile2, $12.3 \%$ in quartile3, and $7.1 \%$ in quartile4 for LDL-C $(P=0.003)$, and was $14.8 \%$ in quartile1, $13.1 \%$ in quartile2, $11.2 \%$ in quartile3, and $6.3 \%$ in quartile4 for Non-HDL-C $(P<0.001)$.

\section{Association of Non-HDL-C and LDL-C with HT}

In the univariate analysis, age $(P<0.001)$, males $(P<0.001)$, atrial fibrillation $(P<0.001)$, smoking $(P=$ 0.033), alcohol consumption ( $P=0.049)$, TOAST classification $(P<0.001)$, NIHSS scores on admission $(P<0.001), \operatorname{SBP}(P<0.001), \mathrm{DBP}(P=0.048)$, thrombolysis $(P<0.001)$, thrombectomy $(P<0.001), \mathrm{TG}$ 
$(P<0.001), \mathrm{TC}(P=0.003), \mathrm{HDL}-\mathrm{C}(P=0.005), \mathrm{LDL}-\mathrm{C}(P<0.001)$ and Non-HDL-C $(P<0.001)$ were significantly associated with $\mathrm{HT}$ (Table 2$)$.

Table 3 shows the association between quartiles of Non-HDL-C or LDL-C and HT. After adjusting for age and sex in model 1, patients in the lower Non-HDL-C quartiles were associated with increased risks of HT ( $P$ for trend $<0.001)$. Compared with the highest quartiles, the first, second and third quartiles of Non-HDL$C$ were associated with increased risk of HT (adjusted ORs 1.74 [95\% Cl 1.09-2.78], 2.01[95\% Cl 1.263.20], and 1.76 [95\% $\mathrm{Cl} 1.10-2.83]$, respectively) after adjusting for age, sex, NIHSS scores on admission, atrial fibrillation, smoking, alcohol consumption, SBP, thrombolysis, thrombectomy and TOAST classification in model 2.

After adjusting age and sex in model 1, patients in the lower LDL-C quartiles were associated with increased risks of HT ( $P$ for trend $<0.001$ ). Compared with the highest quartiles, the first and third quartiles of LDL-C were associated with increased risks of HT (adjusted ORs 1.57 [95\% Cl 1.00-2.47] and 1.82 [95\% Cl 1.16-2.87]), but not the second quartiles (adjusted ORs 1.51 [95\% Cl 0.95-2.40]) after adjusting for age, sex, NIHSS scores on admission, atrial fibrillation, smoking, alcohol consumption, SBP, thrombolysis, thrombectomy and TOAST classification in model 2 (Table 3).

Using a multiple-adjusted spline regression, no nonlinear trend was found between Non-HDL-C, LDL-C and HT (Figure 2). When adding Non-HDL-C or LDL-C to Model2, the c-statistics were $0.79(95 \% \mathrm{Cl} 0.77-0.80$, $P<0.001)$ for Non-HDL-C and $0.78(95 \% \mathrm{Cl} 0.77-0.80, P<0.001)$ for LDL-C (Table 4). In addition, when adding Non-HDL-C, LDL-C to model 2 containing conventional risk factors significantly improved predictive ability (Non-HDL-C, net reclassification index $0.24,95 \% \mathrm{Cl} 0.17-0.31, P<0.001$; LDL-C, net reclassification index $0.15,95 \% \mathrm{Cl} 0.08-0.22, P=0.03$ ) (Table 4).

\section{Patients Age Affects the Relationship between Non-HDL-C and HT}

Age is an interaction factor between Non-HDL-C and $\mathrm{HT}(P=0.021)$. Limiting the analysis to younger patients $(<60)$ showed a significant negative relationship between Non-HDL-C and HT (OR 0.64, 95\%Cl $0.47-0.87), P<0.01)$, whereas this relationship was no longer significant in older patients $(\geq 60)$ (Table 5 ). After adjustment potential confounding variables, we found that the relationship between Non-HDL-C and HT did not change by sex, base NIHSS score, atrial fibrillation, smoking, alcohol consumption, SBP, reperfusion therapy (thrombolysis/thrombectomy) and stroke type (all $P$ for interaction $>0.05$ ) (Table 5).

\section{Discussion}

In the present study, we found low Non-HDL-C was associated with an increased risk of HT in patients with AIS after adjustment for known risk factors. In addition, Non-HDL-C has similar effects as LDL-C for predicting $\mathrm{HT}$. 
Some studies showed that Non-HDL-C was a good biomarker for predicting cardiovascular events[8, 19 , 20]. Despite these data, the role of the Non-HDL-C for HT is still not clear in patients with ischaemic stroke. In the present study, low Non-HDL-C was independently associated with increased risks of HT. In addition, no robust association was observed between LDL-C and HT. Prior studies[4, 21] have shown that low LDL-C was related to greater risk for $\mathrm{HT}$; however, these studies included patients with ischaemic stroke receiving intravenous or intra-arterial rt-PA and mechanical recanalization. Conversely, other research[22-24] stated that LDL-C on admission was not associated with intracerebral hemorrhage after intravenous thrombolysis. In our study, we found lower LDL-C was significantly related to higher risks of $\mathrm{HT}$ in the univariate analysis, but this association was attenuated after adjusting for risk factors, suggesting a possible mediating effect of unmeasured confounders. Further studies are needed to clarify the association especially in general AIS patients.

The mechanisms that explain the association of cholesterol and HT are uncertain, but there are some possible explanations as follows. First, cholesterol may play a great role in keeping the integrity of cerebral vascular vessel. It is reported that low level of cholesterol could cause the increased permeability of the erythrocyte membrane[25], and even contribute to the leakage and rupture of vessels wall[26]. Second, cholesterol is likely to affect aggregation of platelet. Some studies have shown that low level of cholesterol might lead to decreased platelet aggregation, and then increase the risk of bleeding[27]. Third, abnormal blood lipid levels could result in the increased plasma viscosity and whole blood viscosity, and then cholesterol would be accumulated in endangium, thereby exciting the sympathetic nervous system and renin angiotensin system, with the injury of vascular wall[28,29]. Further studies are needed to verify the mechanism between serum lipid levels and HT.

Although increasing evidence[9-11] indicated that Non-HDL-C was superior to LDL-C in terms of predicting the risk of cardiovascular disease, we found Non-HDL-C has similar predictive values as LDL-C for HT in AIS. The addition of Non-HDL-C or LDL-C to a conventional risk factor model could improve predictive ability for $\mathrm{HT}$, suggesting that Non-HDL-C could be a potential predictive marker for $\mathrm{HT}$ as well as LDL-C. Furthermore, Non-HDL-C is more accurate and reliable when measured in the non-fasting sate compared with LDL-C[30]. In addition, some guidelines on the management of blood cholesterol has recommended that Non-HDL-C could be as a primary goal in the primary and secondary prevention of cardiovascular disease[31-33].

In this study, we found Non-HDL-C was negatively associated with HT in younger stroke patients. In older stroke patients, Non-HDL-C is also negatively related to HT even though there was no significant difference. One possible explanation for these findings is that malnutrition is more commonly seen in elderly population[34] and malnutrition might lead to decreased serum cholesterol.[35]

Our study has some limitations. First, patients presented with HT at admission were excluded. Therefore, the results might not be generalizable to all ischaemic stroke patients. However, the proportion of patients with $\mathrm{HT}$ at admission is low (3.9\%) in this study. Second, this study was just an observational, singlecenter study, so the findings might not be generalized to the whole Chinese population. Third, although 
we struggled to obtain medical history, there might be some omissions. Therefore, the results of this study should be interpreted cautiously.

In conclusion, low Non-HDL-C was independently associated with an increased risk of HT. In addition, Non-HDL-C has similar effects as LDL-C for predicting HT. These findings suggest that patients with low Non-HDL-C or LDL-C are prone to haemorrhagic transformation and those might be considered in practice to reduce the risk of haemorrhagic transformation. Further large sample size studies are needed to confirm these findings.

\section{Abbreviations}

HT: haemorrhagic transformation; AIS: acute ischaemic stroke; Non-HDL-C: non-high-density lipoprotein cholesterol; LDL-C: low-density lipoprotein cholesterol; OR: Odds ratio; ORs: Odds ratios Cl: Confidence interval; NRI: net reclassification index; CT: Computed tomography; MRI: Magnetic resonance imaging; SBP: systolic blood pressure; DBP: diastolic blood pressure; TOAST: the Trial of ORG 10172 in Acute Stroke Treatment; NIHSS: National Institutes of Health Stroke Scale; TC: total cholesterol, TG: triglycerides.

\section{Declarations}

\section{Ethics approval and consent to participate}

This study was approved by The Biomedical Research Ethics Committee of West China Hospital, Sichuan University, and conformed to local and international ethical criteria. Informed consent was not required since the study was observational and retrospective in nature.

\section{Consent for publication}

Participants consent for publication: Not applicable.

\section{Competing interests}

The authors declare that they have no competing interests.

\section{Funding}

None

\section{Author Contributions}


Ming Liu and Bo Wu designed the study, guided the data analysis and revised the manuscript. Yanan Wang, Quhong Song, Yajun Cheng and Ye Chen collected the clinical data. Yanan Wang, Quhong Song and Chenchen Wei collected the imaging data. Yanan Wang and Junfeng Liu performed statistics analysis. Yanan Wang and Quhong Song drafted the manuscript. All authors revised the manuscript and approved the final version.

\section{Acknowledgements}

This study was supported by the Major International (Regional) Joint Research Project, National Natural Science Foundation of China (81620108009) and Key Research and Development Program, Science \& Technology Department of Sichuan Province (2017SZ0007), the National Key Research and Development Program of China, Ministry of Science and Technology of China (2016YFC1300500-505).

\section{Availability of data and materials}

The data used in this study are available from the corresponding author upon reasonable request.

\section{References}

1.Tran-Dinh A, Levoye A, Lambert G, Louedec L, Journe C, Meilhac O, Amarenco P: Low levels of lowdensity lipoprotein-C associated with proprotein convertase subtilisin kexin 9 inhibition do not increase the risk of hemorrhagic transformation. Stroke 2014, 45(10):3086-3088.

2.Yaghi S, Willey JZ, Cucchiara B, Goldstein JN, Gonzales NR, Khatri P, Kim LJ, Mayer SA, Sheth KN, Schwamm LH: Treatment and Outcome of Hemorrhagic Transformation After Intravenous Alteplase in Acute Ischemic Stroke: A Scientific Statement for Healthcare Professionals From the American Heart Association/American Stroke Association. Stroke 2017, 48(12):e343-e361.

3.Wu S, Wu B, Liu M, Chen Z, Wang W, Anderson CS, Sandercock P, Wang Y, Huang Y, Cui L et al: Stroke in China: advances and challenges in epidemiology, prevention, and management. The Lancet Neurology 2019, 18(4):394-405.

4.Bang OY, Saver JL, Liebeskind DS, Starkman S, Villablanca P, Salamon N, Buck B, Ali L, Restrepo L, Vinuela $\mathrm{F}$ et al: Cholesterol level and symptomatic hemorrhagic transformation after ischemic stroke thrombolysis. Neurology 2007, 68(10):737-742.

5.Kim BJ, Lee SH, Ryu WS, Kang BS, Kim CK, Yoon BW: Low level of low-density lipoprotein cholesterol increases hemorrhagic transformation in large artery atherothrombosis but not in cardioembolism. Stroke 2009, 40(5):1627-1632.

6.D'Amelio M, Terruso V, Famoso G, Ragonese P, Aridon P, Savettieri G: Cholesterol levels and risk of hemorrhagic transformation after acute ischemic stroke. Cerebrovascular diseases (Basel, Switzerland) 
2011, 32(3):234-238.

7.Yang N, Lin M, Wang BG, Zeng WY, He YF, Peng HY, Zeng J, Wu ZY, Zhong Y: Low level of low-density lipoprotein cholesterol is related with increased hemorrhagic transformation after acute ischemic cerebral infarction. European review for medical and pharmacological sciences 2016, 20(4):673-678.

8.Puri R, Nissen SE, Shao M, Elshazly MB, Kataoka Y, Kapadia SR, Tuzcu EM, Nicholls SJ: Non-HDL Cholesterol and Triglycerides: Implications for Coronary Atheroma Progression and Clinical Events. Arteriosclerosis, thrombosis, and vascular biology 2016, 36(11):2220-2228.

9.Orakzai SH, Nasir K, Blaha M, Blumenthal RS, Raggi P: Non-HDL cholesterol is strongly associated with coronary artery calcification in asymptomatic individuals. Atherosclerosis 2009, 202(1):289-295.

10.Verbeek R, Hovingh GK, Boekholdt SM: Non-high-density lipoprotein cholesterol: current status as cardiovascular marker. Current opinion in lipidology 2015, 26(6):502-510.

11.Sniderman A, McQueen M, Contois J, Williams K, Furberg CD: Why is non-high-density lipoprotein cholesterol a better marker of the risk of vascular disease than low-density lipoprotein cholesterol? Journal of clinical lipidology 2010, 4(3):152-155.

12.Wu B, Lin S, Hao Z, Yang J, Xu Y, Wu L, Zhang S, Liu M: Proportion, risk factors and outcome of lacunar infarction: a hospital-based study in a Chinese population. Cerebrovascular diseases (Basel, Switzerland) 2010, 29(2):181-187.

13.Kong FY, Tao WD, Hao ZL, Liu M: Predictors of one-year disability and death in Chinese hospitalized women after ischemic stroke. Cerebrovascular diseases (Basel, Switzerland) 2010, 29(3):255-262.

14.Aho K, Harmsen P, Hatano S, Marquardsen J, Smirnov VE, Strasser T: Cerebrovascular disease in the community: results of a WHO collaborative study. Bulletin of the World Health Organization 1980, 58(1):113-130.

15.Brott T, Adams HP, Jr., Olinger CP, Marler JR, Barsan WG, Biller J, Spilker J, Holleran R, Eberle R, Hertzberg V et al: Measurements of acute cerebral infarction: a clinical examination scale. Stroke 1989, 20(7):864-870.

16.Jacobson TA, Ito MK, Maki KC, Orringer CE, Bays HE, Jones PH, McKenney JM, Grundy SM, Gill EA, Wild RA et al: National lipid association recommendations for patient-centered management of dyslipidemia: part 1-full report. Journal of clinical lipidology 2015, 9(2):129-169.

17. Hacke W, Kaste M, Fieschi C, von Kummer R, Davalos A, Meier D, Larrue V, Bluhmki E, Davis S, Donnan $\mathrm{G}$ et al: Randomised double-blind placebo-controlled trial of thrombolytic therapy with intravenous alteplase in acute ischaemic stroke (ECASS II). Second European-Australasian Acute Stroke Study Investigators. Lancet 1998, 352(9136):1245-1251. 
18.Pencina MJ, D’Agostino RB, Sr., D’Agostino RB, Jr., Vasan RS: Evaluating the added predictive ability of a new marker: from area under the ROC curve to reclassification and beyond. Statistics in medicine 2008, 27(2):157-172; discussion 207-112.

19.Elshazly MB, Martin SS, Blaha MJ, Joshi PH, Toth PP, McEvoy JW, Al-Hijji MA, Kulkarni KR, Kwiterovich PO, Blumenthal RS et al: Non-high-density lipoprotein cholesterol, guideline targets, and population percentiles for secondary prevention in 1.3 million adults: the VLDL-2 study (very large database of lipids). Journal of the American College of Cardiology 2013, 62(21):1960-1965.

20.Holewijn S, den Heijer M, Swinkels DW, Stalenhoef AF, de Graaf J: Apolipoprotein B, non-HDL cholesterol and LDL cholesterol for identifying individuals at increased cardiovascular risk. Journal of internal medicine 2010, 268(6):567-577.

21.Lin SF, Chao AC, Hu HH, Lin RT, Chen CH, Chan L, Lin HJ, Sun Y, Lin YY, Chen PL et al: Low Cholesterol Levels Increase Symptomatic Intracranial Hemorrhage Rates After Intravenous Thrombolysis: A Multicenter Cohort Validation Study. J Atheroscler Thromb 2018.

22.Hong CT, Chiu WT, Chi NF, Lai LY, Hu CJ, Hu HH, Chan L: Low-density lipoprotein level on admission is not associated with postintravenous thrombolysis intracranial hemorrhage in patients with acute ischemic stroke. J Investig Med 2018, 67(3):659-662.

23.Lin TC, Lin YK, Chen Cl, Chan L, Chi NF, Yuan RY, Sheu JJ, Wei CR, Tsai JP, Yeh TH: Serum lipid level is not associated with symptomatic intracerebral hemorrhage after intravenous thrombolysis for acute ischemic stroke. PeerJ 2018, 6:e6021.

24.Messe SR, Pervez MA, Smith EE, Siddique KA, Hellkamp AS, Saver JL, Bhatt DL, Fonarow GC, Peterson ED, Schwamm LH: Lipid profile, lipid-lowering medications, and intracerebral hemorrhage after tPA in get with the guidelines-stroke. Stroke 2013, 44(5):1354-1359.

25.Wieberdink RG, Poels MM, Vernooij MW, Koudstaal PJ, Hofman A, van der Lugt A, Breteler MM, Ikram MA: Serum lipid levels and the risk of intracerebral hemorrhage: the Rotterdam Study. Arteriosclerosis, thrombosis, and vascular biology 2011, 31(12):2982-2989.

26.Thrift A, McNeil J, Donnan G: Reduced frequency of high cholesterol levels among patients with intracerebral haemorrhage. Journal of clinical neuroscience: official journal of the Neurosurgical Society of Australasia 2002, 9(4):376-380.

27.Fessler MB, Rose K, Zhang Y, Jaramillo R, Zeldin DC: Relationship between serum cholesterol and indices of erythrocytes and platelets in the US population. Journal of lipid research 2013, 54(11):31773188.

28.Rosenson RS, McCormick A, Uretz EF: Distribution of blood viscosity values and biochemical correlates in healthy adults. Clinical chemistry 1996, 42(8 Pt 1):1189-1195. 
29.Rosenson RS, Shott S, Tangney CC: Hypertriglyceridemia is associated with an elevated blood viscosity Rosenson: triglycerides and blood viscosity. Atherosclerosis 2002, 161(2):433-439.

30.Mahajan N, Ference BA, Arora N, Madhavan R, Bhattacharya P, Sudhakar R, Sagar A, Wang Y, Sacks F, Afonso L: Role of non-high-density lipoprotein cholesterol in predicting cerebrovascular events in patients following myocardial infarction. The American journal of cardiology 2012, 109(12):1694-1699.

31.Grundy SM, Stone NJ, Bailey AL, Beam C, Birtcher KK, Blumenthal RS, Braun LT, de Ferranti S, FaiellaTommasino J, Forman DE et al: 2018 AHA/ACC/AACVPR/AAPA/ABC/ACPM/ADA/AGS/APhA/ASPC/NLA/PCNA Guideline on the Management of Blood Cholesterol: A Report of the American College of Cardiology/American Heart Association Task Force on Clinical Practice Guidelines. Journal of the American College of Cardiology 2018.

32.National Cholesterol Education Program Expert Panel on Detection E, Treatment of High Blood Cholesterol in A: Third Report of the National Cholesterol Education Program (NCEP) Expert Panel on Detection, Evaluation, and Treatment of High Blood Cholesterol in Adults (Adult Treatment Panel III) final report. Circulation 2002, 106(25):3143-3421.

33.Zhu J, Gao R, Zhao S, Lu G, Zhao D, Li J: Guidelines for the prevention and treatment of dyslipidemia in Chinese adults (revised edition 2016). Chin Circul J 2016, 31(10):937-953.

34.Zhang Z, Pereira S, Luo M, Matheson E: Evaluation of Blood Biomarkers Associated with Risk of Malnutrition in Older Adults: A Systematic Review and Meta-Analysis. Nutrients 2017, 9(8).

35.Amirkalali B, Sharifi F, Fakhrzadeh H, Mirarefein M, Ghaderpanahi M, Badamchizadeh Z, Larijani B: Low serum leptin serves as a biomarker of malnutrition in elderly patients. Nutrition Research 2010, 30(5):314-319.

\section{Tables}

Table 1 Baseline characteristics of participants according to Non-HDL-C quartiles 


\begin{tabular}{|c|c|c|c|c|c|}
\hline \multirow[t]{3}{*}{ Characteristics } & \multicolumn{4}{|c|}{ Quartiles of Non-HDL, $\mathrm{mmol} / \mathrm{l}$} & \multirow[t]{3}{*}{$P$-value } \\
\hline & $\mathrm{Q} 1,<2.35$ & $\begin{array}{l}\text { Q2 2.35- } \\
3.06\end{array}$ & $\begin{array}{l}\text { Q3 3.07- } \\
3.83\end{array}$ & $\mathrm{Q} 4>3.83$ & \\
\hline & $\mathrm{n}=514$ & $\mathrm{n}=510$ & $\mathrm{n}=511$ & $\mathrm{n}=508$ & \\
\hline Age, (Mean \pm SD), years & $66 \pm 15$ & $65 \pm 14$ & $65 \pm 14$ & $63 \pm 14$ & $<0.001^{\mathrm{a}}$ \\
\hline Male, n (\%) & $\begin{array}{l}327 \\
(63.6 \%)\end{array}$ & $341(66.9 \%)$ & $321(62.8 \%)$ & $\begin{array}{l}301 \\
(59.3 \%)\end{array}$ & $0.093^{b}$ \\
\hline \multicolumn{6}{|l|}{ Medical history, n (\%) } \\
\hline Hypertension, n (\%) & $\begin{array}{l}269 \\
(52.3 \%)\end{array}$ & 265 (52.0\%) & $297(58.1 \%)$ & $\begin{array}{l}301 \\
(59.3 \%)\end{array}$ & $0.030^{\mathrm{b}}$ \\
\hline Diabetes mellitus, n (\%) & $\begin{array}{l}129 \\
(25.1 \%)\end{array}$ & 109 (21.4\%) & $91(17.8 \%)$ & $\begin{array}{l}138 \\
(27.2 \%)\end{array}$ & $0.002^{b}$ \\
\hline Hyperlipidemia, n (\%) & $14(2.7 \% \%)$ & $19(3.7 \%)$ & $17(3.3 \%)$ & $25(4.9 \%)$ & $0.293^{b}$ \\
\hline Atrial fibrillation, $\mathrm{n}(\%)$ & $97(18.9 \%)$ & $62(12.2 \%)$ & $44(8.6 \%)$ & $32(6.3 \%)$ & $<0.001^{b}$ \\
\hline Smoking, n (\%) & $\begin{array}{l}213 \\
(41.4 \%)\end{array}$ & 220 (43.1\%) & $223(43.6 \%)$ & $\begin{array}{l}208 \\
(40.9 \%)\end{array}$ & $0.787^{b}$ \\
\hline Alcohol consumption, $\mathrm{n}(\%)$ & $\begin{array}{l}142 \\
(27.6 \%)\end{array}$ & $141(27.6 \%)$ & $142(27.8 \%$ & $\begin{array}{l}135 \\
(26.6 \%)\end{array}$ & $0.971^{b}$ \\
\hline \multicolumn{6}{|l|}{ TOAST classification } \\
\hline $\begin{array}{l}\text { Large-artery atherosclerosis, } \mathrm{n} \\
\text { (\%) }\end{array}$ & $\begin{array}{l}151 \\
(29.4 \%)\end{array}$ & $156(30.6 \%)$ & $179(35.0 \%)$ & $\begin{array}{l}185 \\
(36.4 \%)\end{array}$ & $<0.001^{\mathrm{b}}$ \\
\hline Small-artery occlusion, n (\%) & $84(16.3 \%)$ & $112(22.0 \%)$ & $132(25.8 \%)$ & $\begin{array}{l}156 \\
(30.7 \%)\end{array}$ & \\
\hline Cardioembolic, n (\%) & $\begin{array}{l}150 \\
(29.2 \%)\end{array}$ & 130 (25.5\%) & $97(19.0 \%)$ & $57(11.2 \%)$ & \\
\hline Undetermined etiology, $\mathrm{n}(\%)$ & $\begin{array}{l}108 \\
(21.0 \%)\end{array}$ & $93(18.2 \%)$ & $87(17.0 \%)$ & $98(19.3 \%)$ & \\
\hline Other etiology, n (\%) & $21(4.1 \%)$ & $19(3.7 \%)$ & $16(3.1 \%)$ & $12(2.4 \%)$ & \\
\hline NIHSS on admission, median (IQR) & $6(2-13)$ & $6(2-11)$ & $5(2-11)$ & $5(2-10)$ & $0.002^{\mathrm{c}}$ \\
\hline SBP, (Mean \pm SD), mmHg & $141 \pm 22$ & $144 \pm 23$ & $147 \pm 24$ & $151 \pm 23$ & $<0.001^{\mathrm{a}}$ \\
\hline DBP, (Mean \pm SD), $\mathrm{mmHg}$ & $82 \pm 14$ & $85 \pm 14$ & $87 \pm 15$ & $88 \pm 15$ & $<0.001^{a}$ \\
\hline Glucose, (Mean \pm SD), mmol/L & $7.61 \pm 2.92$ & $7.67 \pm 3.06$ & $7.62 \pm 2.96$ & $8.98 \pm 4.44$ & $<0.001^{\mathrm{a}}$ \\
\hline Thrombolysis, n (\%) & $31(6.0 \%)$ & $22(4.3 \%)$ & $21(4.1 \%)$ & $33(6.5 \%)$ & $0.216^{\mathrm{b}}$ \\
\hline Thrombectomy, n (\%) & $33(6.4 \%)$ & $24(4.3 \%)$ & $22(4.3 \%)$ & $23(4.5 \%)$ & $0.386^{\mathrm{b}}$ \\
\hline \multicolumn{6}{|l|}{ Lipid profile } \\
\hline $\mathrm{TG},($ Mean $\pm \mathrm{SD}), \mathrm{mmol} / \mathrm{L}$ & $1.11 \pm 0.72$ & $1.36 \pm 0.84$ & $1.74 \pm 1.03$ & $2.53 \pm 1.88$ & $<0.001^{\mathrm{a}}$ \\
\hline $\mathrm{TC},($ Mean $\pm \mathrm{SD}), \mathrm{mmol} / \mathrm{L}$ & $3.14 \pm 0.55$ & $3.97 \pm 0.41$ & $4.63 \pm 0.41$ & $5.81 \pm 0.84$ & $<0.001^{\mathrm{a}}$ \\
\hline HDL-C, $($ Mean \pm SD), mmol/L & $1.29 \pm 0.41$ & $1.25 \pm 0.36$ & $1.23 \pm 0.36$ & $1.19 \pm 0.35$ & $0.001^{\mathrm{a}}$ \\
\hline LDL-C, $($ Mean \pm SD), mmol/L & $1.58 \pm 0.40$ & $2.33 \pm 0.30$ & $2.87 \pm 0.36$ & $3.79 \pm 0.77$ & $<0.001^{\mathrm{a}}$ \\
\hline Non-HDL, (Mean \pm SD), mmol/L & $1.86 \pm 0.36$ & $2.72 \pm 0.20$ & $3.40 \pm 0.22$ & $4.62 \pm 0.78$ & $<0.001^{\mathrm{a}}$ \\
\hline
\end{tabular}

Abbreviations: NHISS, National Institutes of Health Stroke Scale; SBP: systolic blood pressure; DBP: diastolic blood pressure; TG: triglyceride; TC: total cholesterol; LDL-C: low-density lipoprotein cholesterol; HDL-C: high-density lipoprotein cholesterol. Non-HDL-C: non-high-density lipoprotein cholesterol.

a ANOVA test

b Chi-squared test

c Kruskal-Wallis test 
Table 2 Univariate analysis to identify risk factors associated with haemorrhagic transformation in patients with acute ischaemic stroke

\begin{tabular}{|c|c|c|c|c|}
\hline Characteristic & $\begin{array}{l}\text { Total patients } \\
(\mathrm{n}=2043)\end{array}$ & $\begin{array}{l}\text { With HT } \\
(\mathrm{n}=232)\end{array}$ & $\begin{array}{l}\text { Without HT } \\
(\mathrm{n}=1811)\end{array}$ & $P$-value \\
\hline Age (Mean \pm SD), years & $65 \pm 14$ & $68 \pm 14$ & $64 \pm 14$ & $<0.001^{\mathrm{a}}$ \\
\hline Males, n (\%) & $1290(63.1 \%)$ & $113(48.7 \%)$ & $1177(65.0 \%)$ & $<0.001^{b}$ \\
\hline \multicolumn{5}{|l|}{ Medical history, n (\%) } \\
\hline Hypertension, n (\%) & $1132(55.4 \%)$ & $115(49.5 \%)$ & 1017 (56.2\%) & $0.864^{\mathrm{b}}$ \\
\hline Diabetes mellitus, n (\%) & $467(22.9 \%)$ & $52(22.4 \%)$ & $415(22.9 \%)$ & $0.528^{b}$ \\
\hline Hyperlipidemia, n (\%) & $75(3.7 \%)$ & $7(3.0 \%)$ & $68(3.8 \%)$ & $0.574^{\mathrm{b}}$ \\
\hline Atrial fibrillation, n (\%) & 235 (11.5\%) & $69(29.7 \%)$ & $166(9.2 \%)$ & $<0.001^{b}$ \\
\hline Smoking, n (\%) & $864(42.3 \%)$ & $83(35.8 \%)$ & $781(43.1 \%)$ & $0.033^{b}$ \\
\hline Alcohol consumption, n (\%) & $560(27.4 \%)$ & $51(22.0 \%)$ & $509(28.1 \%)$ & $0.049^{b}$ \\
\hline \multicolumn{5}{|l|}{ TOAST classification } \\
\hline $\begin{array}{l}\text { Large-artery atherosclerosis, } \\
\text { n (\%) }\end{array}$ & $671(32.8 \%)$ & $73(31.5 \%)$ & $598(33.0 \%)$ & $<0.001^{b}$ \\
\hline Small-artery occlusion, n (\%) & $484(23.7 \%)$ & $4(1.7 \%)$ & $480(26.5 \%)$ & \\
\hline Cardioembolic, n (\%) & $434(21.2 \%)$ & $111(47.8 \%)$ & $323(17.8 \%)$ & \\
\hline Undetermined etiology, n (\%) & $386(18.9 \%)$ & $40(16.1 \%)$ & $346(19.3 \%)$ & \\
\hline Other etiology, n (\%) & $68(3.3 \%)$ & $4(1.7 \%)$ & $64(3.5 \%)$ & \\
\hline $\begin{array}{l}\text { NIHSS on admission, median } \\
\text { (IQR) }\end{array}$ & $5(2-10)$ & $11(6-18)$ & $5(2-10)$ & $<0.001^{\mathrm{c}}$ \\
\hline SBP, $($ Mean \pm SD), $\mathrm{mmHg}$ & $146 \pm 23$ & $140 \pm 23$ & $146 \pm 23$ & $<0.001^{\mathrm{a}}$ \\
\hline $\mathrm{DBP},($ Mean $\pm \mathrm{SD}), \mathrm{mmHg}$ & $85 \pm 15$ & $84 \pm 16$ & $86 \pm 15$ & $0.048^{\mathrm{a}}$ \\
\hline Glucose, $($ Mean $\pm \mathrm{SD}), \mathrm{mmol} / \mathrm{L}$ & $7.97 \pm 3.45$ & $8.16 \pm 2.52$ & $7.94 \pm 3.55$ & $0.233^{\mathrm{a}}$ \\
\hline Thrombolysis, n (\%) & $107(5.2 \%)$ & $27(11.6 \%)$ & $80(4.4 \%)$ & $<0.001^{b}$ \\
\hline Thrombectomy, n (\%) & $102(5.0 \%)$ & $24(10.3 \%)$ & $78(4.3 \%)$ & $<0.001^{\mathrm{b}}$ \\
\hline \multicolumn{5}{|l|}{ Lipid profile } \\
\hline $\mathrm{TG},($ Mean $\pm \mathrm{SD}), \mathrm{mmol} / \mathrm{L}$ & $1.68 \pm 1.32$ & $1.37 \pm 1.01$ & $1.72 \pm 1.35$ & $<0.001^{\mathrm{a}}$ \\
\hline $\mathrm{TC},($ Mean $\pm \mathrm{SD}), \mathrm{mmol} / \mathrm{L}$ & $4.38 \pm 1.13$ & $4.18 \pm 1.11$ & $4.41 \pm 1.14$ & $0.003^{\mathrm{a}}$ \\
\hline HDL-C, $($ Mean \pm SD), mmol/L & $1.24 \pm 0.37$ & $1.32 \pm 0.44$ & $1.23 \pm 0.36$ & $0.005^{\mathrm{a}}$ \\
\hline LDL-C, $($ Mean \pm SD), $\mathrm{mmol} / \mathrm{L}$ & $2.64 \pm 0.95$ & $2.44 \pm 0.86$ & $2.66 \pm 0.95$ & $<0.001^{\mathrm{a}}$ \\
\hline $\begin{array}{l}\text { Non-HDL-C, (Mean } \pm \text { SD), } \\
\mathrm{mmol} / \mathrm{L}\end{array}$ & $3.14 \pm 1.11$ & $2.86 \pm 1.05$ & $3.18 \pm 1.11$ & $<0.001^{\mathrm{a}}$ \\
\hline
\end{tabular}

Abbreviations: NHISS, National Institutes of Health Stroke Scale; SBP: systolic blood pressure; DBP: diastolic blood pressure; TG: triglyceride; TC: total cholesterol; LDL-C: low-density lipoprotein cholesterol; HDL-C: high-density lipoprotein cholesterol. Non-HDL-C: non-high-density lipoprotein cholesterol.

a Student's $t$ test

b Chi-squared test 
c Mann-Whitney Test

Table 3 Association of quartiles of Non-HDL-C, LDL-C and hemorrhagic transformation

\begin{tabular}{|c|c|c|c|c|c|c|}
\hline & \multicolumn{2}{|l|}{ Crude } & \multicolumn{2}{|l|}{ Model 1} & \multicolumn{2}{|l|}{ Model 2} \\
\hline & OR $(95 \% \mathrm{CI})$ & $P$-value & OR $(95 \% \mathrm{CI})$ & $P$-value & OR $(95 \% \mathrm{CI})$ & $P$-value \\
\hline \multicolumn{7}{|l|}{ Non-HDL-C } \\
\hline Q1 & $2.58(1.67-3.98)$ & $<0.001$ & $2.60(1.68-4.03)$ & $<0.001$ & $1.74(1.09-2.78)$ & 0.019 \\
\hline Q2 & $2.25(1.45-3.50)$ & $<0.001$ & $2.34(1.50-3.66)$ & $<0.001$ & $2.01(1.26-3.20)$ & 0.003 \\
\hline Q3 & $1.87(1.19-2.93)$ & 0.007 & $1.88(1.19-2.97)$ & $<0.001$ & $1.76(1.10-2.83)$ & 0.019 \\
\hline Q4 & 1 & & 1 & & 1 & \\
\hline $\begin{array}{l}P \text { for trend } \\
\text { LDL-C }\end{array}$ & $<0.001$ & & $<0.001$ & & 0.024 & \\
\hline Q1 & $2.20(1.45-3.33)$ & $<0.001$ & $2.26(1.48-3.44)$ & $<0.001$ & $1.57(1.00-2.47)$ & 0.049 \\
\hline Q2 & $1.70(1.10-2.62)$ & 0.017 & $1.77(1.14-2.75)$ & 0.011 & $1.51(0.95-2.40)$ & 0.079 \\
\hline Q3 & $1.83(1.19-2.81)$ & 0.006 & $1.85(1.20-2.85)$ & 0.005 & $1.82(1.16-2.87)$ & 0.009 \\
\hline Q4 & 1 & & 1 & & 1 & \\
\hline$P$ for trend & 0.001 & & $<0.001$ & & 0.121 & \\
\hline
\end{tabular}

Abbreviations: OR, odds ratio. CI, confidence interval. Non-HDL-C: non-high-density lipoprotein cholesterol; LDL-C: low-density lipoprotein cholesterol. Model 1, adjusted for age, sex; Model, 2, adjusted for model 1 and further adjusted for NIHSS scores on admission, atrial fibrillation, smoking, alcohol consumption, SBP, thrombolysis, thrombectomy and TOAST classification.

Table 4 C statistics and net reclassification index for HT by Non-HDL-C, LDL-C among patients with acute ischaemic stroke

\begin{tabular}{lllll}
\hline Variable & C statistics (95\%CI) & $P$-value & NRI (95\%CI) & $P$-value \\
\hline Non-HDL-C & $0.59(0.55-0.63)$ & $<0.001$ & NA & NA \\
LDL-C & $0.57(0.53-0.61)$ & 0.001 & NA & NA \\
Non-HDL-C + Model 2 & $0.79(0.77-0.80)$ & $<0.001$ & $0.24(0.17-0.31)$ & $<0.001$ \\
LDL-C + Model 2 & $0.78(0.77-0.80)$ & $<0.001$ & $0.15(0.08-0.22)$ & 0.03 \\
\hline
\end{tabular}

Model 2 adjusted for age, sex, NIHSS scores on admission, atrial fibrillation, smoking, alcohol consumption, SBP, thrombolysis, thrombectomy and TOAST classification. NRI, net reclassification improvement. 
Table 5 Stratified logistic regression analysis to identify variables that modify the correlation between Non-HDL-C and haemorrhagic transformation

\begin{tabular}{|c|c|c|}
\hline & OR (95\%CI), P-value* & $P$ for interaction* \\
\hline \multicolumn{3}{|l|}{ Age } \\
\hline$<60$ & $0.64(0.47-0.87), \mathrm{P}<0.001$ & 0.021 \\
\hline$\geq 60$ & $0.95(0.81-1.12), 0.523$ & \\
\hline \multicolumn{3}{|l|}{ Sex } \\
\hline Male & $0.78(0.64-0.96) 0.021$ & 0.188 \\
\hline Female & $0.95(0.78-1.15) 0.586$ & \\
\hline \multicolumn{3}{|c|}{ Baseline NIHSS score } \\
\hline$<15$ & $0.90(0.76-1.06) 0.217$ & 0.363 \\
\hline$\geq 15$ & $0.78(0.59-1.02) 0.069$ & \\
\hline \multicolumn{3}{|l|}{ Atrial Fibrillation } \\
\hline No & $0.82(0.69-0.96) 0.016$ & 0.151 \\
\hline Yes & $1.05(0.78-1.40) 0.760$ & \\
\hline \multicolumn{3}{|l|}{ Smoking } \\
\hline No & $0.89(0.74-1.06) 0.190$ & 0.655 \\
\hline Yes & $0.83(0.66-1.04) 0.109$ & \\
\hline \multicolumn{3}{|c|}{ Alcohol consumption } \\
\hline No & $0.91(0.78-1.07) 0.261$ & 0.160 \\
\hline Yes & $0.71(0.53-0.97) 0.032$ & \\
\hline \multicolumn{3}{|l|}{ SBP } \\
\hline$<140$ & $0.91(0.74-1.11) 0.338$ & 0.404 \\
\hline$\geq 140$ & $0.80(0.66-0.98) 0.031$ & \\
\hline \multicolumn{3}{|c|}{ Reperfusion therapy (Thrombolysis/Thrombectomy) } \\
\hline No & $0.86(0.74-1.01) 0.070$ & 0.944 \\
\hline Yes & $0.88(0.62-1.24) 0.452$ & \\
\hline \multicolumn{3}{|l|}{ Stroke type } \\
\hline Non-cardioembolic & $0.79(0.66-0.95) 0.013$ & 0.134 \\
\hline Cardioembolic & $0.99(0.79-1.25) 0.953$ & \\
\hline
\end{tabular}

*Above model adjusted for age, sex, NIHSS scores on admission, atrial fibrillation, smoking, alcohol consumption, SBP, thrombolysis, thrombectomy and Stroke type. In each case, the model is not adjusted for the stratification variable.

Abbreviations: NHISS, National Institutes of Health Stroke Scale; SBP: systolic blood pressure

\section{Figures}




\section{6 consecutive patients with acute ischemic stroke within 7 days}

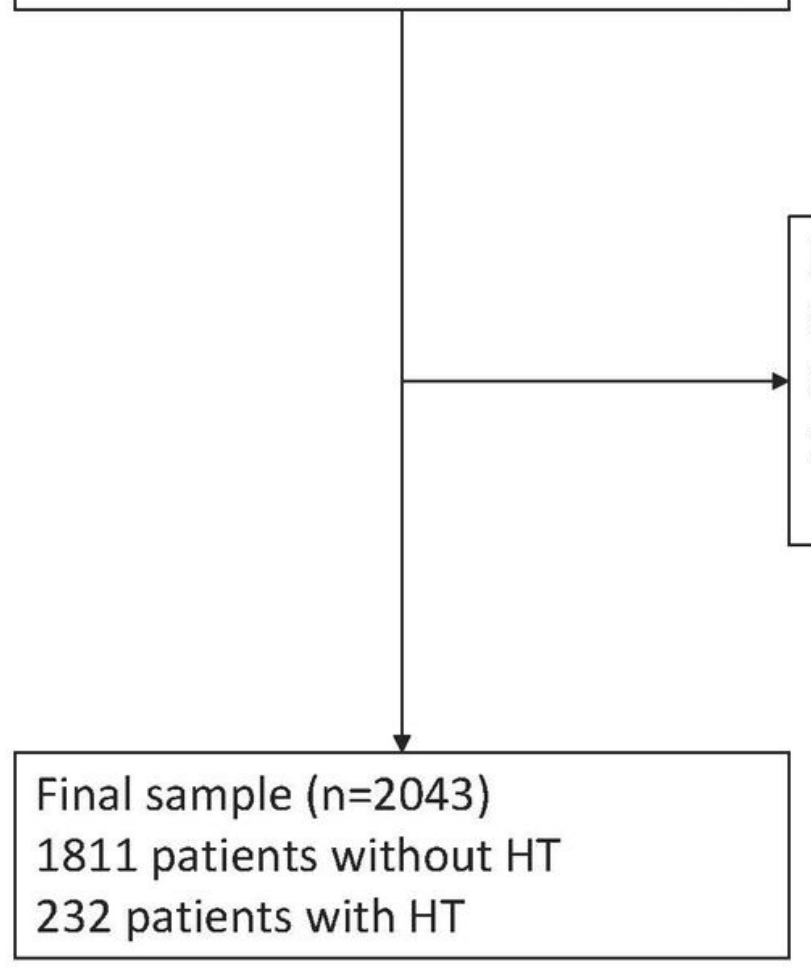

\section{Exclusion $(n=163)$}

85 patients with HT on admission;

67 patients without a second CT or MRI scan

11 patients without lipid profile results within $24 \mathrm{~h}$ after admission

\section{Figure 1}

Study patients flow chart. HT: haemorrhagic transformation. 

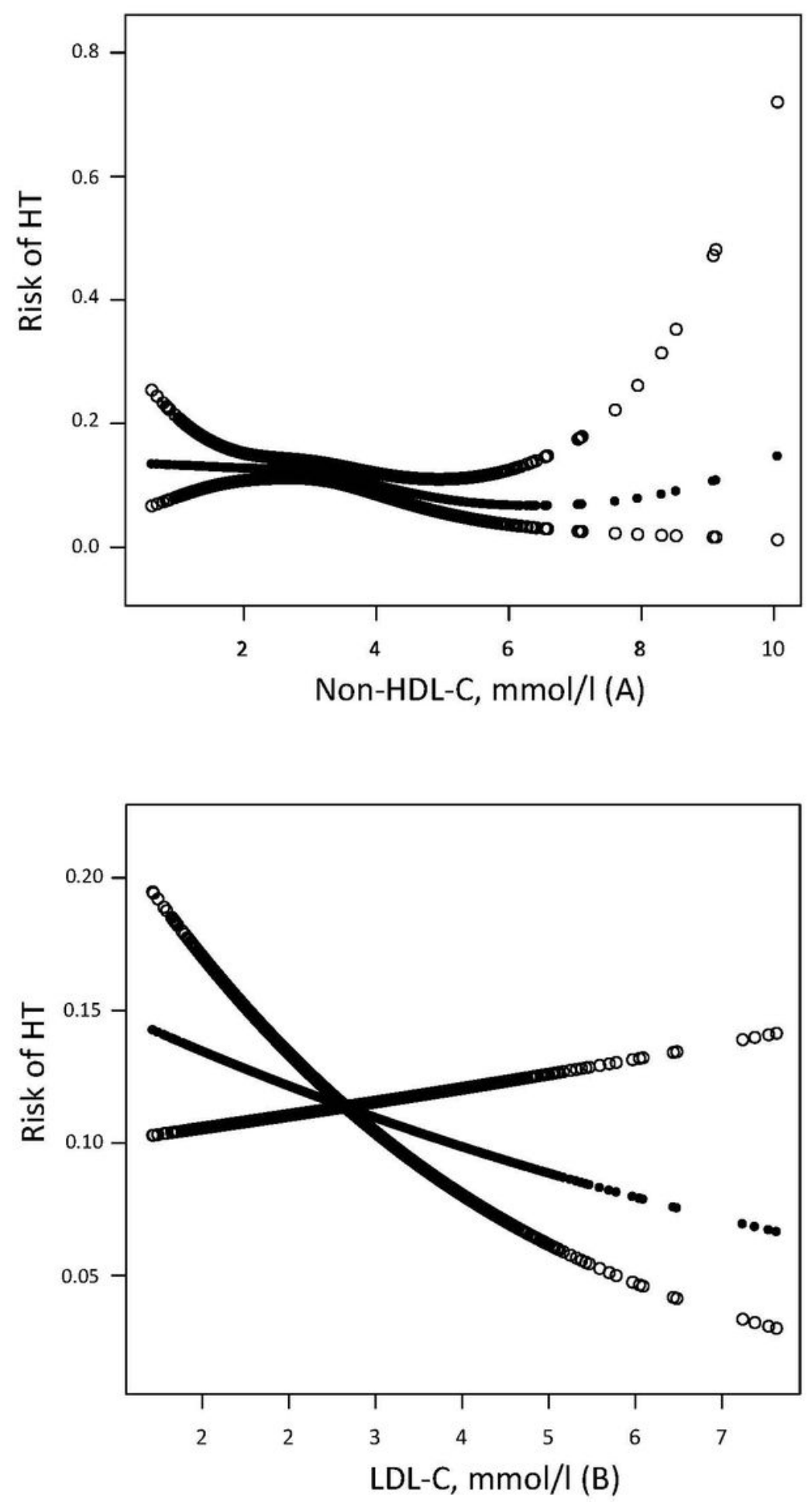

Figure 2

Relationship of Non-HDL-C (A), LDL-C (B) with risk of haemorrhagic transformation after acute ischaemic stroke. Risk of haemorrhagic transformation and $95 \%$ confidence intervals determined using the generalized additive model. 